\title{
Greenhouse Gas Mitigation Strategies for Container Shipping Industry
}

\author{
Lin Shimin and Wong Yiik Diew \\ School of Civil and Environmental, \\ Engineering Nanyang Technological University, Singapore
}

\begin{abstract}
With the onset of the first ever Greenhouse Gas (GHG) regulation for ships by the International Maritime Organisation (IMO) in 2011, the container shipping industry requires the combined use of technical and operational emissions reduction measures to improve the environmental performance of its vessels. Studies show that most existing measures are cost effective with a range of emissions reduction potential. However, the level of implementation is not depicted and the potential of the measures may be over-estimated. An evaluation of the emissions reduction measures is conducted through the examination of 3 factors, namely level of implementation, emissions reduction potential and cost effectiveness. Strategies to overcome the critical barriers of implementation are suggested in this study. Lastly, recommendations for companies with regards to GHG issues are made. The strong link between cost effectiveness and level of implementation is highlighted in this study. It is also shown that there is immense potential to reduce emissions from ships given the availability of measures with significant reduction potential. However, the top barriers of implementation, namely cost of measure and lack of information, need to be addressed for a higher level of adoption. This report serves as the first step to map strategy for managing GHG in the shipping industry. The importance of cost effectiveness in decision making from a ship operators perspective prompts the adoption of measures that are the most cost effective first before measures with high emissions reduction potential. It is prudent for shipping companies to adopt a more environmentally friendly operation as green is the way forward in the shipping industry.
\end{abstract}

Keywords: GHG Emissions Reduction Measures, Level of Implementation, Emissions Reduction Potential, Cost Effectiveness, Environmentally Friendly, Shipping Industry, Heavy Fuel Oil (HFO)

\section{INTRODUCTION}

With the increase of attention on environmental protection by the international community, the shipping industry faces mounting pressure to play its part in the reduction of Greenhouse Gas (GHG) emissions. For shipping activities, GHG emissions mainly come from the burning of Heavy Fuel Oil (HFO), the main maritime transport fuel for sea-going vessels. The amount of impurities in HFO results in the release of harmful GHG such as Carbon dioxide $\left(\mathrm{CO}_{2}\right)$ and Nitrogen Oxides $\left(\mathrm{NO}_{\mathrm{X}}\right)$ (Crist, 2009). GHG emissions from ships were largely unregulated until the introduction of the first ever Corresponding Author: Lin Shimin, School of Civil and Environmental, Engineering Nanyang Technological University, Singapore

international GHG regulation for ships by the International Maritime Organisation (IMO) in 2011. With the onset of the new regulations, shipping companies are required to improve the efficiency of their new and existing vessels. The IMO, in the second IMO GHG study 2009, has proposed possible technical and operational measures that can be adopted by ship operators for control of GHG emissions from ships (Buhaug et al., 2009). It is important for shipping companies to adopt cost effective measures that can achieve the required efficiencies so as to manage the environmental concerns without affecting the economic performance of the company (Lun et al., 2010). In addition, companies are increasingly competing on environmental YlPs Science Publications 310 
performance and customers are also selecting service providers based on their environmental performance (Hart and Ahuja, 1996). It is a competitive advantage to be seen as an environmentally friendly company. Therefore, the benefit of a well-planned GHG mitigation strategy is enormous.

The objective of this study is to investigate the GHG mitigation strategies of container liner shipping industry amid the increased need for companies to be environmentally friendly. Studies show that most existing measures are cost effective with a range of emissions reduction potential (Alvik, 2010; Eide et al., 2009; Faber et al., 2009). However, the level of implementation is not depicted and the potential of the measures may be overestimated. An evaluation of the implementation of various GHG emissions reduction measures is thus conducted. Critical issues in the implementation of measures are identified so that solutions can be provided. This study also provides conclusions and recommendations about the position companies should take with regards to GHG issues. The scope of the project includes evaluating the perception of shipping companies towards current GHG emissions reduction measures and identifying critical issues through extensive literature reviews, surveys and interviews. For the present study, the research focuses on container liner vessels and excludes other types of commercial vessels such as tankers and bulk carriers.

\section{MATERIALS AND METHODS}

Primary research was conducted through a twopronged approach of surveys and interviews. Survey questionnaires were posted to the top 100 container liner shipping companies. A small number of survey responses were anticipated and therefore the surveys were used to capture ground information. The interviews with classification society, governmental agency and selected shipping companies serve as the second pillar of the primary information collection in this study.

\subsection{Emissions Reduction Measures}

Annual reports of companies and information from public domain were reviewed extensively to identify GHG emissions reduction measures that are adopted by shipping companies.

Emissions reduction can be achieved through operational and technical measures. Operational measures see Table 1 relate to the way that the ship is maintained and operated. They are near-term mitigation measures that can have an almost immediate effect on emissions reduction across the existing fleet without huge investments and physical changes to the ship. On the other hand, technical measures see Table 2 often require substantial upfront investment cost, but these measures usually have significant potential for emissions reduction.

\subsection{Emissions Reduction Potential and Cost Effectiveness}

The measures are evaluated by agencies mainly using the two factors, namely emissions reduction potential and cost effectiveness. The adoption of GHG reduction measures arises from the need to protect the environment. Therefore, the ability of the measures to reduce emissions is a major consideration. However, a cost effective GHG emissions reduction policy is also equally important for a company's competitive advantage. Cost effectiveness is defined as the monetary evaluation of the cost of implementing the measure and the cost savings that can be achieved through the usage of the measure over the investment timeframe. The cost of measure can include, for example, the direct cost of the equipments used to improve performance of the vessel and the opportunity cost incurred due to loss of earnings if retrofitting is not arranged with dry docking. The most significant cost savings comes from the reduction in fuel usage as the adoption of measures has a direct impact on the amount of bunker consumption. A measure is cost effective if the financial benefit from reduced fuel cost offsets the cost of the investment.

For a shipping company, the best measure is one that is the most cost effective while achieving a high level of emissions reduction. However, such measures hardly exist. There is often a trade-off between emissions reduction potential and cost effectiveness. An understanding of the evaluation of the measures from the ship operators' perspective is thus necessary to identify the more important factor. This can be done by surveying the extent to which existing measures are being implemented.

\subsection{Critical Issues of Implementation}

A range of barriers (Table 3) hinder the implementation of emissions reduction measures by ship operators. The critical issues are identified in this section mainly with reference to Kollamthodi et al. (2008) and through interviews conducted at the initial stage of this study. The level of barriers will be examined so that possible solution can be provided to overcome the barriers. 
Table 1. Operational measures

Optimisation of trim and ballast

Propeller, hull and engine maintenance

Speed reduction

Weather routing

Table 2. Technical measures

Alternative fuels and power sources

Cold-ironing

Concept, speed and capability

Hull and superstructure designs

Hull coatings

Power and propulsion systems upgrades

Waste heat recovery

Table 3. Critical issues of implementation

Lack of information

Cost of measure

Hidden cost

Owner-user problem

Technological and infrastructure constraints

Materiality

\section{RESULTS AND DISCUSSION}

\subsection{Level of Implementation, Emissions Reduction Potential and Cost Effectiveness}

The emissions reduction measures were evaluated based on 3 factors, namely level of implementation, emissions reduction potential and cost effectiveness.

Survey results show that the level of implementation of operational measures is generally higher than technical measures Fig. 1. The top 3 emissions reduction measures implemented are operational measures, namely speed reduction, propeller, hull and engine maintenance and optimisation of trim and ballast. Operational measures are low-hanging fruits that are adopted in the day-to-day operations without requiring expensive retrofit to improve efficiency. They have high cost effectiveness and generally have higher level of implementation despite lower emissions reduction potential. The higher level of adoption of operational measures highlights the importance of cost effectiveness in decision making.

It is also shown that the level of implementation does not exactly follow the emissions reduction potential. The general trend is that the higher the perceived cost effectiveness, the higher the level of implementation. It is suggested that improving the cost efficiency of the measures will evoke a higher level of implementation.

Measures are also recognised to have a rather consistent medium-high potential but the level of implementation is more variable. There is immense potential for greater utilisation of current measures given the relatively high perceived potential. More efforts will need to be focused on making the measures more attractive to ship operators in terms of cost to improve their level of implementation. This is especially so for technical measures since they have a higher level of perceived potential than implementation. Operational measures show a reverse trend and hence, more RandD is needed to improve the emissions reduction potential of the measures.

From findings in survey and interviews, the relationship between emissions reduction potential, cost effectiveness and level of implementation, can be established Fig. 2. In general, measures with higher emissions reduction potential do not have a high level of implementation. This is mainly influenced by the cost effectiveness of the measures. An improvement in reduction potential comes with cost. A lower cost effectiveness of the measure will lead to lower level of implementation due to the importance of cost factor in the decision making of companies. Therefore, the main factor that should be addressed would be the cost effectiveness of the measures.

\subsection{Critical Issues of Implementation}

Examination of the factors used for evaluation of measures shows the cost aspect of implementation to be of great concern for companies Fig. 3. The most critical barrier to implementation is also cost related Fig. 4. Similarly, interview respondents highlighted the significant amount of investment required for some measures as a significant hindrance to implementation. For example, the US\$10 million investment required for the waste heat recovery system and the uncertainty of return on investment in the range of 5 to 10 years deter the implementation of the measure. The decision to install such cost intensive measures will be dependent upon the level of risk and commitment that the company is willing to take for environmental issues.

The lack of information is also seen as a significant barrier. Industry representatives interviewed agreed that there is a need for more accurate information regarding abatement costs and opportunities of the measures. There are many energy saving technologies with claims of significant savings but they are usually tested under specific conditions which ships do not have the chance to meet. Respondents felt that the availability of reliable information will enhance their confidence to implement the measures. 
Lin Shimin and Wong Yiik Diew / American Journal of Engineering and Applied Sciences 5 (4) (2012) 310-317

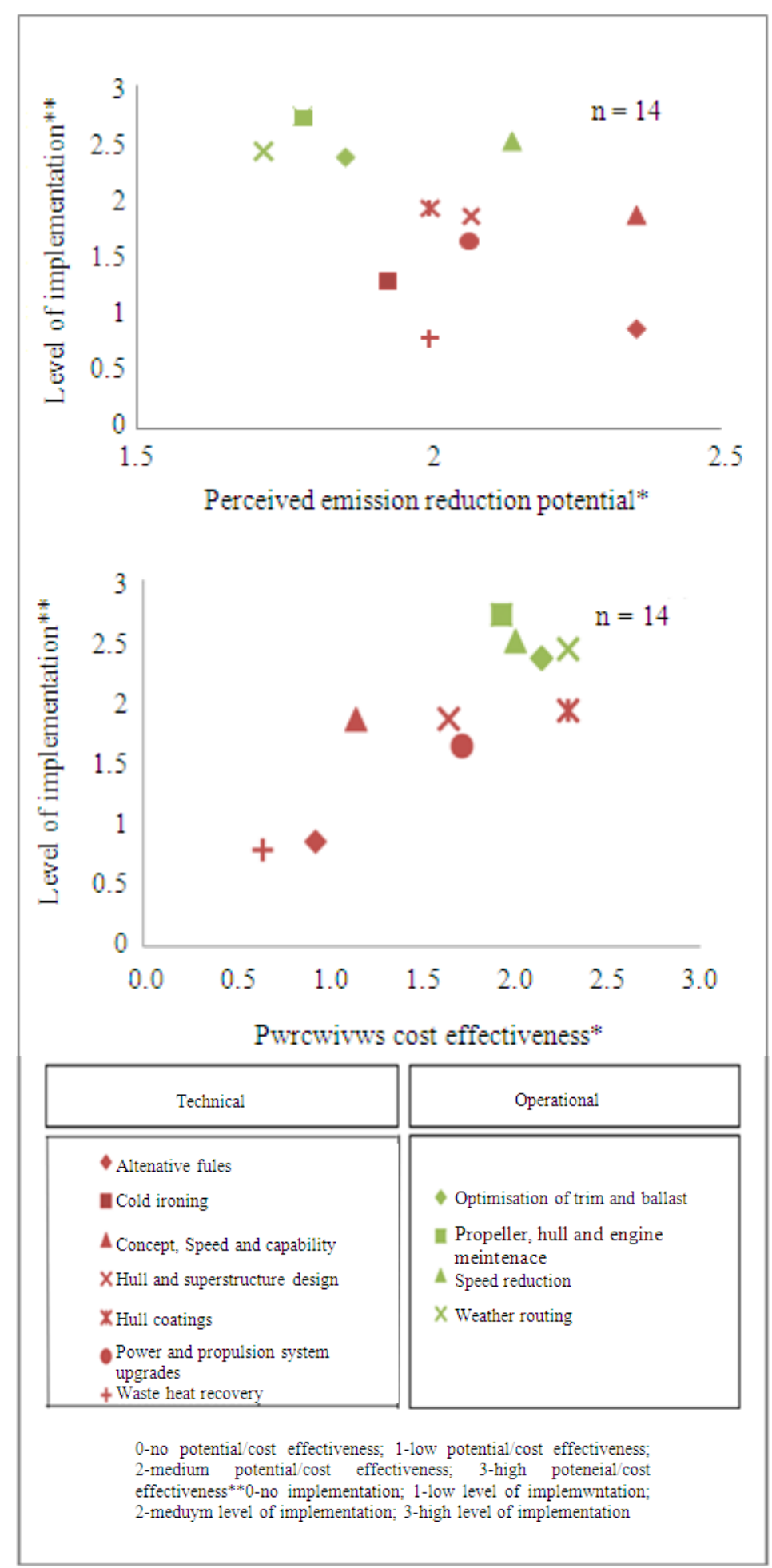

Fig. 1. Perceived emissions reduction potential, cost effectiveness and level of implementation 


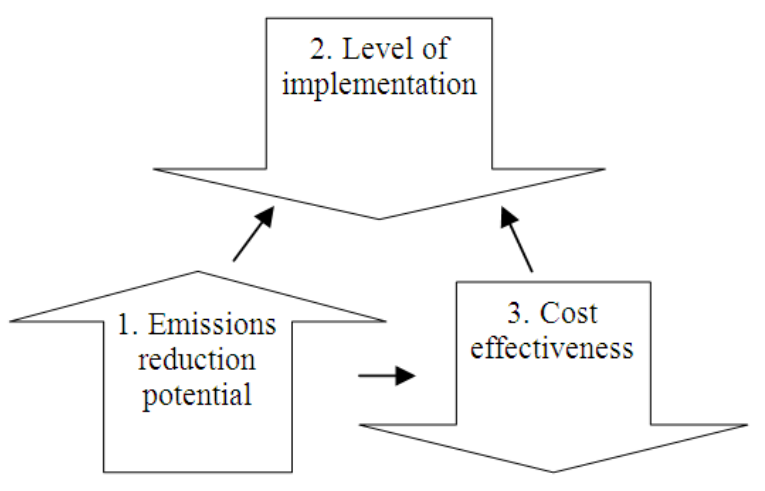

Fig. 2. Relationship between emission reduction potential, cost effectiveness and level of implementation

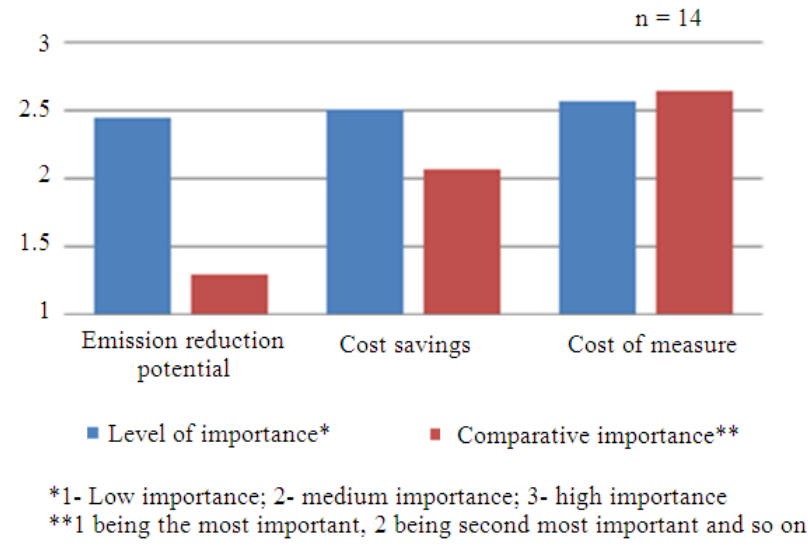

Fig. 3. Factors used for evaluation of measures

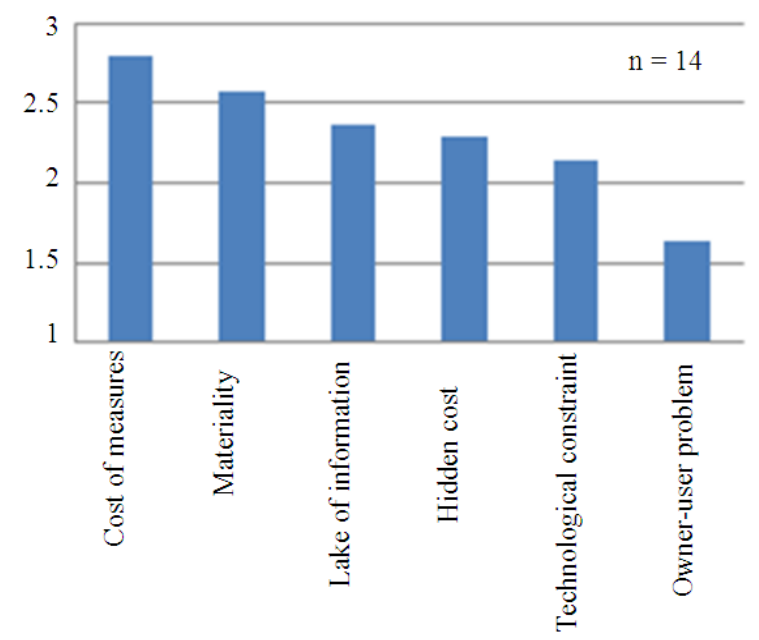

*1- Limited hindrance; 2-Some hindrance; 3-Substantial hindrance

Fig. 4. Critical issues of implementation
Despite being ranked highly in the survey, interview respondents generally felt that materiality is not considered a critical barrier as measures with low materiality are usually more cost effective. Measures with lower materiality can be implemented on a wide scale due to its cost effectiveness. However, sufficient research on the applicability for the particular ship and monitoring need to be conducted to ensure its feasibility.

Respondents expressed the views that the barriers to implementation inevitably result in higher financial burden. A reduction of these barriers will make the measures more cost effective and will result in a higher level of implementation. Thus, the main consideration during implementation boils down to cost effectiveness of the measures.

\subsection{Choosing the Right Measures}

With the importance of cost effectiveness in mind, the recommended stages of implementation are summarised in Fig. 5. Companies can first implement measures that are cost effective and have a high emissions reduction potential, followed by the consideration of the cost effective measures with lower potential. Eventually, when such measures are exhausted, companies can implement the less cost effective measures.

The framework is exemplified through the categorisation of measures using the survey results on perceived cost effectiveness and emissions reduction potential. As shown in Fig. 6, there are no measures categorised under cost effective-high potential. Ship operators should then adopt measures in the cost effectivelow potential category such as weather routing and speed reduction. These measures can be implemented by shipping companies without the need for much risk analysis. This is then followed by the implementation of less cost effective-high potential measures such as alternative fuel. These measures require much more detailed risk analysis as they constitute high risk and high chance of failure. Lastly, measures that are low cost effective-low potential should in theory not be implemented. However, they may be needed to comply with regulations. Choosing the right measures will involve taking regulations into consideration.

\subsection{Overcoming Critical Barriers}

Survey and interview responses show that cost of measure and lack of information are the top critical issues of implementation of measures. 


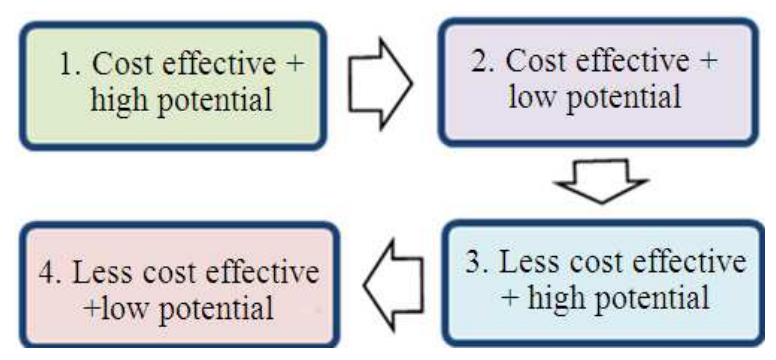

Fig. 5. Recommended stages of implementation of measures

\begin{tabular}{|l|l|}
\hline $\begin{array}{l}\text { 1. Cost effective } \\
\text { + high potential }\end{array}$ & $\begin{array}{l}\text { 3. Less cost effective } \\
\text { + high potential }\end{array}$ \\
\hline None & Alternative fuel \\
\hline $\begin{array}{ll}\text { 2. Cost effective } \\
\text { + Low potential }\end{array}$ & $\begin{array}{l}\text { Concept, speed and } \\
\text { capability }\end{array}$ \\
\cline { 1 - 1 } Hull and superstructure design & $\begin{array}{l}\text { 4. Low cost effective } \\
\text { + Low potential }\end{array}$ \\
\hline Hull coatings & Cold ironing \\
\hline Optimisation of trim and ballast & $\begin{array}{l}\text { Power and propulsion } \\
\text { system upgrades }\end{array}$ \\
\cline { 1 - 1 } $\begin{array}{l}\text { Propeller, hull and engine } \\
\text { maintenance }\end{array}$ & Waste heat recovery \\
\cline { 1 - 1 } Speed reduction & \\
\cline { 1 - 1 } Weather routing &
\end{tabular}

Fig. 6. Categorisation of measures

For cost of measure, interview respondents indicate that this barrier is likely to erode naturally as fuel prices increase. The measures will get increasingly cost effective due to the savings in fuel consumption. Also, with the increasing uptake of the more cost effective measures, there may be a bottleneck where companies will have to look at those measures that may not be that cost effective in order to achieve the improvement in vessels' efficiency. This cost barrier will also decrease when market condition improves. Respondents believed that the market condition has amplified the importance of the cost factor in the consideration of the uptake of measures. This cost barrier will erode with an improvement in economic situation. Nevertheless, respondents agreed that monetary incentives to improve the cost efficiency of the measures will aid in a more rapid erosion of this barrier. With external monetary support, companies may be more willing to implement the measures with high emissions reduction potential as cost barrier is significantly reduced.

For lack of information, it is advisable for companies to use their own efforts to verify the information provided by external agents. This can be done through dedicated in-house research departments. Collaboration with universities, various agencies and other companies to develop and trial test new solutions is also useful. A more active participation by companies can assist in overcoming the barrier caused by the inadequacy of information provided by external agents. Risk sharing contracts between technology suppliers and owners for claims made for various technologies are also suggested as a possible solution. Better consolidation of information is also practical in addressing ship operators' concern. The fathom guide to ship efficiency is an example of a valuable guide compiling technologies and measures available in the market for ship operators who are searching for information on reduction of emissions from ships. Ship operators are more receptive of measures that have gone through large scale project to verify the efficiency of the measures. The guide provides a consolidation of data from demonstration projects that have been conducted and will assist in the decision making process.

\subsection{Moving Ahead}

Companies must recognise that an improvement in environmental performance can reduce cost and increase revenue. GHG emissions reduction is a common byproduct of energy efficiency improvements on ships. Such improvements reduce fuel consumption and hence result in cost savings. Companies should implement the measures on a higher level in view of the cost savings from a reduction in fuel usage. Companies can also ride on the environmental issues to do more business. The shipment of the green equipments is a valuable business opportunity to leverage on for the next ten to fifteen years. Companies can also market themselves as being more environmentally friendly and take on market share from other modes of transportation.

Marketing is an important component of the GHG mitigation strategies. Shipping companies should focus on marketing and publicising their green efforts. Many of the emissions reduction measures are used in the dayto-day operations to increase operational efficiency. Companies can carefully market these as environmental initiatives. One good marketing tactic is to move ahead of the regulations as a first-mover strategy can help to build up a company's reputation. Table 4 shows some of the environmental related efforts that are seen as good marketing opportunities. 
Table 4. Marketing opportunities

Voluntary use of indicators to evaluate and publicly report on environmental progress

Participation in major environmental initiatives such as CCWG Issuance of regular environmental reports

Availability of information regarding emissions control through websites, brochures and publications

Provision of carbon calculator

It is expected that regulations regarding $\mathrm{GHG}$ emissions will get increasingly stringent. It would be prudent for companies to adopt the emissions reduction measures incrementally as the best way to counter regulations is not to meet them but to anticipate and beat them. Shipping companies can refer to IMO and professional consultants for guidance on the new regulations. More importantly, companies should view the regulations as beneficial. Better emissions control technologies will be available as air pollution from ships becomes increasingly regulated. Regulations can drive R\&D to bring about greater cost effectiveness and emissions reduction potential of existing and new measures. Therefore, support for the regulations is encouraged especially in view of the high bunker prices.

\section{CONCLUSION}

Evaluating and selecting measures using appropriate decision criteria is an imperative component of a good GHG strategy. The importance of cost effectiveness in decision making from a ship operator's perspective is highlighted in this study. This prompts the adoption of measures that are most cost effective first before measures with high emissions reduction potential. It is advisable for companies to consider savings from reduction in fuel consumption as a main factor in selecting measures, especially with the increasing cost of fuel. Companies should also monitor demand changes amid the environmental situation to identify business opportunities. With the careful packaging of the GHG strategy, the environmental issue can be valuable for business creation. It is also vital to examine the development of new regulations and work closely with consultants to determine the best measures for achieving the required efficiency.

There is immense potential to reduce emissions given the availability of measures with significant reduction potential. However, the top barriers of implementation, namely cost of measures and lack of information, need to be addressed for a higher level of adoption. It is probable that there will be development of more energy efficient technologies at a faster pace in the future as regulations tighten. Ship operators can expect to gain from a wider selection of promising measures and services as more resources are gathered for the improvement of energy efficiency. Support for the regulations is thus encouraged. It is prudent for shipping companies to adopt a more environmentally friendly operation as green is the way forward in the shipping industry.

The technical and operational measures that were chosen for this study are the existing measures in the market that have published data on emissions reduction potential. There are sub-categories of measures that were not addressed in this study. Upcoming technologies such as wind energy were also not included in this study. Further research can assess the economic, social and environmental impacts of these measures. A follow-up project on market-based measures would also allow for a more comprehensive study of the overall strategies that can adopted by ship operators. Lastly, more detailed study on the critical barriers for specific measures is encouraged so that enabler schemes can be devised to remove or overcome the barriers.

\section{REFERENCES}

Alvik, S., M.S. Eide, O. Endresen, P. Hoffmann and T. Longva, 2010. Pathways to low carbon shipping Abatement potential towards 2030. DNV De Norske Veritas.

Buhaug, O., J.J. Corbett, O. Endresen, V. Eyring and J. Faber et al., 2009. Second IMO GHG study. International Maritime Organization (IMO) London, UK.

Crist, P., 2009. Greenhouse gas emissions reduction potential from international shipping. Joint Transport Research Centre of the OECD and the International Transport Forum.

Eide, M.S., O. Endresen, R. Skjong, T. Longva and S. Alvik, 2009. Cost-effectiveness assessment of CO2 reducing measures in shipping. Maritime Policy Manage., 36: 367-384. DOI: 10.1080/03088830903057031

Faber, J., A. Markowska, D. Nelissen, M. Davidson and V. Eyring et al., 2009. Technical support for European action to reducing Greenhouse Gas Emissions from international maritime transport. Manchester Metropolitan University.

Hart, S.L. and G. Ahuja, 1996. Does it pay to be green? An empirical examination of the relationship between emission reduction and firm performance. Bus. Strategy Environ., 5: 30-37. DOI: 10.1002/(SICI)1099-0836(199603)5:1<30::AIDBSE38>3.0.CO;2-Q 
Lin Shimin and Wong Yiik Diew / American Journal of Engineering and Applied Sciences 5 (4) (2012) 310-317

Kollamthodi, S., C. Brannigan, M. Harfoot, I. Skinner and C. Whall et al., 2008. Greenhouse gas emissions from shipping: Trends, projections and abatement potential. AEA Energy Environ.
Lun, Y.H.V., K.W. Pang and P.M. Panayides, 2010. Organisational growth and firm performance in the international container shipping industry. Int. J. Shipp. Tran. Logist., 2: 206-223. DOI: 10.1504/IJSTL.2010.030867 